\title{
The Technical Efficiency of Essential Public Health Services Provision in China: Based on a Panel Data Analysis
}

\section{Fankun Cao}

Shandong University Cheeloo College of Medicine https://orcid.org/0000-0002-8193-749X

\section{Yan Xi}

Health Commission of Shandong Province

Tongyu Bai

health commission of Shandong province

Shushan Dong

Health Commission of Shandong Province

Qiang Sun ( $\nabla$ qiangs@edu.com )

Shandong University Cheeloo College of Medicine

\section{Research}

Keywords: technical efficiency, public health services, panel data analysis, China

Posted Date: June 16th, 2021

DOI: https://doi.org/10.21203/rs.3.rs-605891/v1

License: (c) (1) This work is licensed under a Creative Commons Attribution 4.0 International License. Read Full License 
The technical efficiency of essential public health services provision in China: based on a panel data analysis

\author{
Fankun $\mathrm{Cao}^{1,2}$ Yan $\mathrm{Xi}^{3,4}$ Tongyu $\mathrm{Bai}^{5}$ Shushan Dong ${ }^{6} \quad$ Qiang Sun ${ }^{1,2}$
}

Fankun Cao $\quad \underline{\text { cfk1202@163. com }}$

Qiang Sun qiangs@edu. com

1. Centre for Health Management and Policy Research, School of Public Health, Cheeloo College of Medicine, Shandong University, Jinan, 250012, China.

2. NHC Key Lab of Health Economic and Policy Research (Shandong University), Jinan, 250012, China.

Yan Xi 813671679@qq. com

3. Health Commission of Shandong Province, Jinan, 250014, China.

4. Shandong First Medical University, Jinan, 250012, China.

Tongyu Bair695819696@qq. com

5. Primary Health Department, Health Commission of Shandong Province, Jinan, 250117, China.

Shushan Dong dongshushan@163. com

6. Financial Management Department, Health Commission of Shandong Province, Jinan, 250117, China. 


\section{Declarations}

- Ethics approval and consent to participate

Not applicable.

- Consent for publication

Not applicable.

- Availability of data and materials

The datasets generated and/or analysed during the current study are not publicly available due [REASON WHY DATA ARE NOT PUBLIC] but are available from the corresponding author on reasonable request.

- Competing interests

The authors declare that they have no competing interests.

- Funding

Not applicable.

- Authors' contributions

Fankun Cao' s work included conceptualization, data curation, formal analysis, methodology, resources, software, validation, visualization, writing-original draft, writing-review \& editing.

Yan Xi's work included conceptualization, project administration, supervision, writing-review \& editing.

Tongyu Bai's work included data curation, investigation.

Shushan Dong' s work included data curation, investigation.

Qiang Sun' s work included conceptualization, data curation, project 
administration, supervision, visualization, writing-review \& editing.

- Acknowledgements

Not applicable. 


\section{Abstract}

\section{Background}

Providing essential public health services equally to all Chinese is one of the objectives of health system reform since 2009. Essential public health service program is to provide a package of public health services for all Chinese freely by the primary health institutions. Since the implementation of the national essential public health service program, the level of funding and the intensity of input have been continuously increasing. However, in the context of China's economic development entering a new normal phase, the growth rate of funding for essential public health services has far exceeded the growth rate of GDP and central fiscal revenue, and the sustainability of the development of national essential public health service programs has been seriously challenged. Improving the efficiency of resource use may be an effective way to ensure the continuation of the national essential public health service program. But little evidence was available about technical efficiency in essential public health services provision. Therefore, the aim of this study was to assess the technical efficiency of essential public health services in Shandong province.

\section{Methods}

This study was a retrospective study based on the historical panel data of Shandong Province, East China. The data came from the Shandong Provincial Essential public health Service Program Database of the Medical Management Center of Shandong 
Provincial Health Commission, which covered all 137 counties and districts in 16 cities of Shandong Province from 2014 to 2019. The principal component analysis method was used to classify multiple output indicators of essential public health service programs, so as to achieve the purpose of generic index extraction. The efficiency coefficient transformation analysis method was used to transform the data of each principal component score after the principal component analysis of the input index of essential public health service programs. The CCR model and BBC model in the Data Envelopment Analysis (DEA) method were used to calculate the comprehensive technical efficiency, pure technical efficiency and scale efficiency of essential public health services.

\section{Results}

The average comprehensive technical efficiency of essential public health services in Shandong Province showed a slight downward trend from 0.8896 in 2014 to 0.8753 in 2019 . The average pure technical efficiency of essential public health services was kept at 0.99 . The average scale efficiency of essential public health services showed a slight downward trend from 0.8871 in 2014 to 0.8744 in 2019. The proportion of counties and districts with the comprehensive technical efficiency of essential public health services in Shandong Province was increased from 15. 3\% in 2014 to $21.9 \%$ in 2019. But the proportion of counties with the pure technical efficiency decreased from 38. 0\% in 2014 to 35. 9\% in 2019. The proportion of counties with scale efficiency of essential public health services showed an upward trend, 
rising from $14.8 \%$ in 2014 to $22.6 \%$ in 2019, increasing by $7.8 \%$.

The ratio of effective comprehensive technical efficiency of essential public health services in Shandong Province to all counties and districts has shown a upward trend. Among them, the proportion of counties with effective pure technical efficiency was higher than the proportion of counties with efficient scale efficiency each year. At the same time, the increase in the proportion of counties with effective scale efficiency was higher than the increase in the proportion of counties with effective pure technical efficiency. The increasing proportion of effective counties in the comprehensive technical efficiency of essential public health services in Shandong Province was mainly due to the increasing proportion of effective counties in the scale efficiency and the good performance of effective counties in the pure technical efficiency. This showed that, although the investment scale of Shandong Province in the counties was gradually sufficient, there was still a phenomenon of insufficient resource investment in most counties. That would ultimately affect the sustainability of the implementation of essential public health services.

\section{Conclusion}

The research have demonstrated that the technical efficiency of essential public health services in Shandong Province has shown a slight downward trend, and the main reason for its downward trend was the decline in scale efficiency. The scale efficiency in essential public health services affected the technical efficiency 
and would ultimately threaten the sustainable development of essential public health services. It is recommended that future research directions should focus on the influencing factors and improvement measures of the scale efficiency of essential public health services.

\section{Introduction}

The essential public health services (abbreviated as EPHS in the following) are public service products determined by the government based on the priority of the main health problems that endanger the country and citizens in a specific period, as we11 as the country's available funding and service capacity [1]. EPHS are of great significance to improving the health of residents and narrowing the gap of residents' health status [2-3]. The national essential public health service program is one of the five major contents of deepening medical reform and a major measure to implement the strategy of "Healthy China" in the new era [4]. Essential public health service program is a non-profit health service program freely provided by the government and implemented by the primary health care institutions to children, pregnant women, the elderly and patients with chronic diseases as the key groups 
[5]. The program is a national public health intervention program with the broadest coverage, the largest service population and the highest investment since the founding of the People's Republic of China [6-8].

Since the implementation of the national essential public health service program, the service funds have been provided in the form of fully public financing by governments at all level, and the funding and the intensity of input have been continuously increasing. The ever-increasing investment of public health funds showed that the government attached great importance to public health undertakings, and also provided financial guarantee for the promotion of essential public health service programs [9]. The level of funding has increased from 15 Yuan per capita in 2009 to 74 Yuan per capita in 2020, and funding has increased nearly five times in ten years. Over the past 11 years since the implementation of the national essential public health service program, the accumulated financial investment was over 300 billion Yuan by governments at all levels [10]. The central government has subsidized a total of 169.2 billion Yuan in subsidies, accounting for 55\% of the all levels governments' financial investment [11]. In 2020, the COVID-19 epidemic occurred with the fastest transmission rate, the widest scope of infection and the most difficulty in prevention and control since the founding of the People' s Republic of China. The state has paid more attention to EPHS, raised funding standards, and released nearly $85 \%$ of the subsidy funds in advance. The central budget for EPHS totaled 60.33 billion Yuan in 2020, an increase of $79.4 \%$ compared to 33.63 billion Yuan in 2016 and an increase of $61.1 \%$ compared to 37.45 billion Yuan in 2017. 
However, on the basis of scientific analysis of domestic and foreign economic development situation, the Party Central Committee elaborated on China' s entry into the "new normal of economic development" stage [12-14]. The sustainability of the development of national essential public health service programs has become an issue worthy of consideration [15-16]. Improving the efficiency of allocation and utilization of essential public health service input resources has become the focus of the country's future work in this field [17]. According to the National Bureau of Statistics report, the GDP growth rate in 2020 was 2. 3\% year on year, which was 5 percentage points lower than the $7.3 \%$ in 2014, showing a downward trend. The growth rate of central fiscal revenue in 2020 was $-3.9 \%$ year on year, which was a decrease of 12.5 percentage points from $8.6 \%$ in 2014, showing an obvious downward trend.

The sustainability of national EPHS will be seriously challenged if the previous investment trend is unrealistic after the national economic development has entered the new normal [18]. Therefore improving the efficiency of health resource utilization have become possible effective ways to ensure the sustainable development of national essential public health service programs [19-23].

What is the current situation of technical efficiency of EPHS provision? This question is an important issue that policy makers, practitioners and academic researchers pay close attention to, and it has become an important problem that needs to be solved in theory and practice in the implementation of national essential public health service program [24-25].

It is necessary and urgent to study the efficiency of national essential public 
health service in theory and practice [26-29]. From the perspective of health economics, this study used metrological methods, taking Shandong Province as an example, to study the status quo of essential public health service technical efficiency. Our research provided objective basis and theoretical guidance for the adjustment of relevant policies and work practices of the national essential public health service projects in the next step.

\section{Methods}

This study was conducted in Shandong Province, East China. There are 16 cities, 137 counties (districts) in Shandong Province. The permanent residents was 100 million (7.2\% of the total population in the Chinese mainland), the proportion of urban population and rural population in the province was comparable, and the population ranked second in the country by 2020. Shandong' s gross domestic product (GDP) was 7. 31 trillion Yuan (about $\$ 1.12$ trillion). Shandong was a microcosm of China in terms of population and economic development. ( China National Bureau of Statistics, $2020)$.

\subsection{Data source}

The Shandong Provincial Essential Public Health Service Program Database covered al1 137 counties and districts in 16 cities of Shandong Province from 2014 to 2019. The database was filled in and reported by the primary medical institutions in 16 
cities of Shandong Province on an annual basis, reflecting the essential public health service programs in the district county-level in accordance with the annual county level. The database is reviewed by the health administrative departments at all levels and finally summarized and reported.

The key indicators of essential public health service program database were shown in Table 1. It included 24 indicators of 13 types of service contents.

Table 1 The key indicators of essential public health service program

\begin{tabular}{|c|c|c|}
\hline Types of Service Contents & Key Indicator & Connotation of Key Indicators \\
\hline $\begin{array}{l}\text { Health records management } \\
\text { services for residents }\end{array}$ & $\begin{array}{l}\text { Filing rate of health records } \\
\qquad(\%)\end{array}$ & $\begin{array}{c}\text { Number of registered persons/number of permanent } \\
\text { residents in the jurisdiction } * 100 \%\end{array}$ \\
\hline & $\begin{array}{l}\text { Filing rate of electronic health } \\
\text { records (\%) }\end{array}$ & $\begin{array}{l}\text { Number of residents with electronic health } \\
\text { records/number of permanent residents in the } \\
\text { jurisdiction } * 100 \%\end{array}$ \\
\hline & $\begin{array}{l}\text { Utilization rate of health } \\
\text { records (\%) }\end{array}$ & $\begin{array}{l}\text { Number of files with dynamic records in the } \\
\text { files/the total number of files } * 100 \%\end{array}$ \\
\hline Health Education Services & $\begin{array}{l}\text { Number of Health Education Talks } \\
\text { (Number) }\end{array}$ & Number of Health Education Talks \\
\hline & $\begin{array}{l}\text { Number of Health Lectures } \\
\text { Attended (Person) }\end{array}$ & Number of Health Lectures Attended \\
\hline Vaccination Services & Certificate issuance rate (\%) & $\begin{array}{l}\text { Number of people who have established vaccination } \\
\text { certificate in the annual jurisdiction/number of }\end{array}$ \\
\hline
\end{tabular}




\begin{tabular}{|c|c|c|}
\hline & & $\begin{array}{l}\text { people who should have established vaccination } \\
\text { certificate in the annual jurisdiction } * 100 \%\end{array}$ \\
\hline $\begin{array}{l}\text { Health management services } \\
\text { for children aged } 0 \text { to } 6 \\
\text { years }\end{array}$ & Neonatal visit rate (\%) & $\begin{array}{l}\text { Number of newborns received once and visited by } \\
\text { petition/number of live births in the jurisdiction } \\
\text { in the year* } 100 \%\end{array}$ \\
\hline & Child heal th management rate (\%) & $\begin{array}{l}\text { Number of children aged } 0 \text { to } 6 \text { years old who received } \\
1 \text { or more follow-up visits in the annual } \\
\text { jurisdiction/number of children aged } 0 \text { to } 6 \text { years } \\
\text { old in the annual jurisdiction } * 100 \%\end{array}$ \\
\hline $\begin{array}{c}\text { Maternal health management } \\
\text { services }\end{array}$ & $\begin{array}{l}\text { Early pregnancy enrollment rate } \\
\qquad(\%)\end{array}$ & $\begin{array}{l}\text { Number of women registered before } 13 \text { weeks of } \\
\text { gestation and having their first prenatal check-up } \\
\text { in the area/number of live births in the area during } \\
\text { that period } * 100 \%\end{array}$ \\
\hline & Postpartum visit rate $(\%)$ & $\begin{array}{l}\text { Number of maternal people who have received } \\
\text { postpartum visits } 28 \text { days after the birth of women } \\
\text { in the jurisdiction / number of live births in the } \\
\text { area during that time period } * 100 \%\end{array}$ \\
\hline $\begin{array}{l}\text { Heal th management services } \\
\text { for the elderly }\end{array}$ & $\begin{array}{l}\text { Health management rate for the } \\
\text { elderly (\%) }\end{array}$ & $\begin{array}{l}\text { Number of persons aged } 65 \text { or above receiving health } \\
\text { management/number of permanent residents aged } 65 \text { or } \\
\text { above in the jurisdiction within the year } * 100 \%\end{array}$ \\
\hline $\begin{array}{l}\text { Health management services } \\
\text { for hypertensive patients }\end{array}$ & $\begin{array}{l}\text { Standard management rate of } \\
\text { Hypertensive Patients (\%) }\end{array}$ & $\begin{array}{c}\text { Number of hypertension patients under health } \\
\text { management according to the standard }\end{array}$ \\
\hline
\end{tabular}




\begin{tabular}{|c|c|c|}
\hline & & $\begin{array}{l}\text { requirements/number of hypertension patients under } \\
\text { management within the year } * 100 \%\end{array}$ \\
\hline & $\begin{array}{l}\text { Blood pressure control rate of } \\
\text { management population (\%) }\end{array}$ & $\begin{array}{l}\text { Number of patients whose blood pressure reached the } \\
\text { target in the last follow-up within the year/number } \\
\text { of patients with hypertension under management } \\
\text { within the year } * 100 \%\end{array}$ \\
\hline $\begin{array}{l}\text { Health management services } \\
\text { for patients with type } 2 \\
\text { diabetes }\end{array}$ & $\begin{array}{l}\text { Standard management rate of } \\
\text { patients with type } 2 \text { diabetes } \\
(\%)\end{array}$ & $\begin{array}{l}\text { Number of patients with type } 2 \text { diabetes under health } \\
\text { management according to the specification/number } \\
\text { of patients with type } 2 \text { diabetes under management } \\
\text { within the year } * 100 \%\end{array}$ \\
\hline & $\begin{array}{l}\text { Glucose control rate of } \\
\text { management population (\%) }\end{array}$ & $\begin{array}{l}\text { Number of patients with fasting blood glucose } \\
\text { meeting the criteria in the last follow-up within } \\
\text { the year/number of patients with type } 2 \text { diabetes } \\
\text { under management within the year } * 100 \%\end{array}$ \\
\hline $\begin{array}{l}\text { Management services for } \\
\text { people with severe mental } \\
\text { disorders }\end{array}$ & $\begin{array}{l}\text { Standard management rate of } \\
\text { patients with severe semen } \\
\text { concentration }(\%)\end{array}$ & $\begin{array}{l}\text { Number of patients with severe mental disorders } \\
\text { managed according to the standard } \\
\text { requirements/number of patients with confirmed } \\
\text { severe mental disorders registered in the } \\
\text { jurisdiction within the year } * 100 \%\end{array}$ \\
\hline $\begin{array}{l}\text { Tuberculosis patient } \\
\text { health management services }\end{array}$ & $\begin{array}{l}\text { Tuberculosis patient management } \\
\text { rate }(\%)\end{array}$ & $\begin{array}{l}\text { Number of tuberculosis patients under } \\
\text { management/number of tuberculosis patients } \\
\text { confirmed by the medical institutions appointed by }\end{array}$ \\
\hline
\end{tabular}




\begin{tabular}{|c|c|c|}
\hline & & $\begin{array}{l}\text { the superior and informed by the basic medical } \\
\text { institutions for management in the same period in } \\
\text { the jurisdiction } * 100 \%\end{array}$ \\
\hline & $\begin{array}{c}\text { Regular drug taking rate in } \\
\text { patients with tuberculosis (\%) }\end{array}$ & $\begin{array}{l}\text { Number of tuberculosis patients who took their } \\
\text { medication as required/number of tuberculosis } \\
\text { patients who completed treatment in the same period } \\
\text { in the jurisdiction } * 100 \%\end{array}$ \\
\hline $\begin{array}{l}\text { Traditional Chinese } \\
\text { Medicine health management } \\
\text { services }\end{array}$ & $\begin{array}{l}\text { Traditional Chinese Medicine } \\
\text { health management rate for the } \\
\text { elderly (\%) }\end{array}$ & $\begin{array}{l}\text { Number of residents aged } 65 \text { and above receiving } \\
\text { Traditional Chinese Medicine health management } \\
\text { services/number of permanent residents aged } 65 \text { and } \\
\text { above within the jurisdiction within the year } * 100 \%\end{array}$ \\
\hline & $\begin{array}{l}\text { Traditional Chinese Medicine } \\
\text { health management rate of } \\
\text { children aged } 0 \text { to } 36 \text { months (\%) }\end{array}$ & $\begin{array}{l}\text { Number of children from } 0 \text { to } 36 \text { months who receive } \\
\text { Traditional Chinese Medicine health management } \\
\text { services in accordance with the monthly age in the } \\
\text { jurisdiction / number of children from } 0 \text { to } 36 \\
\text { months who should be managed in the jurisdiction } \\
\qquad * 100 \%\end{array}$ \\
\hline $\begin{array}{l}\text { Services for reporting and } \\
\text { handling infectious } \\
\text { diseases and public health } \\
\text { emergencies }\end{array}$ & $\begin{array}{c}\text { Reporting rate of infectious } \\
\text { diseases (\%) }\end{array}$ & $\begin{array}{c}\text { Number of infectious disease cases reported } \\
\text { online/number of registered infectious disease } \\
\text { cases } * 100 \%\end{array}$ \\
\hline & Timely reporting rate of & Number of timely cases reported/number of \\
\hline
\end{tabular}




\begin{tabular}{|c|c|c|}
\hline & infectious diseases (\%) & infectious disease cases reported $* 100 \%$ \\
\hline Public health emergency & Number of information related to public health \\
& information reporting rate (\%) & emergencies reported in time/number of information \\
\hline Health and family planning & Health and Family Planning & Number of incidents or clues reported/Number of \\
supervision and & Supervision and Co-management $* 100 \%$ & incidents or clues found $* 100 \%$ \\
\hline coordination services & Information Reporting Rate (\%) & \\
\hline
\end{tabular}

\subsection{Data analysis}

\subsubsection{Selection and analysis methods of input and output indicators}

There were certain basis for choosing the above input and output indexes in this study. Based on the relevant systems of EPHS and the actual implementation of EPHS, our research finally formulated the input and output indicators for measuring the technical efficiency of EPHS.

The input of EPHS mainly included three aspects, namely financial input (essential public health service subsidy funds), human input (public health staff) and material input (material expenditure). The output of EPHS included 24 indicators of 13 types of service contents (The 24 indicators was shown in Table 1).

In order to make full and effective use of data, we conducted principal component analysis on the output indicators of EPHS. Through principal component analysis, 
a small number of principal components are summarized from the original variables of many basic public health service output indicators, so as to retain as much information of the original variables as possible to explain the internal structure of multiple variables [30-31]. Principal component analysis could simplify and reduce the dimensionality of basic public health service output indicators, revealing the profound internal laws of things more simply and intuitively [32-34].

Assuming that there are $\mathrm{n}$ cases of the original data collected, each case has the value of $\mathrm{m}$ indicators, and the original variables are denoted $\mathrm{asx}_{1}, \mathrm{x}_{2}, \cdots$, $\mathrm{x}_{\mathrm{m}}$, then the specific steps of extracting principal components by using principal component analysis are as follows,

(1) Standardize the original index data

$$
X_{i j}=\frac{X_{i j-\bar{X}}}{S_{j}}, j=1,2,3, \cdots, m
$$

$\mathrm{X}_{\mathrm{ij}}$ is the data index after standardization, and $\mathrm{X}$ is the data matrix after standardization, then

$$
X=\left(\begin{array}{cccc}
\mathrm{X}_{11} & \mathrm{X}_{12} & \cdots & \mathrm{X}_{1 \mathrm{~m}} \\
\mathrm{X}_{21} & \mathrm{X}_{22} & \cdots & \mathrm{X}_{2 \mathrm{~m}} \\
\vdots & \vdots & \ddots & \vdots \\
\mathrm{X}_{\mathrm{n} 1} & \mathrm{X}_{\mathrm{n} 2} & \ddots & \mathrm{X}_{\mathrm{nm}}
\end{array}\right)
$$

(2) Calculate the correlation matrix $\mathrm{R}$ of $\mathrm{X}$

The normalized covariance matrix of $\mathrm{X}, \mathrm{Cov}(\mathrm{X})$ is 


$$
\mathrm{R}=\operatorname{Cov}(X)=\left(\begin{array}{cccc}
\mathrm{r}_{11} & \mathrm{r}_{12} & \cdots & \mathrm{r}_{1 \mathrm{~m}} \\
\mathrm{r}_{21} & \mathrm{r}_{22} & \cdots & \mathrm{r}_{2 \mathrm{~m}} \\
\vdots & \vdots & & \vdots \\
\mathrm{r}_{\mathrm{n} 1} & \mathrm{r}_{\mathrm{n} 2} & \ddots & \mathrm{r}_{\mathrm{nm}}
\end{array}\right)=\left(\begin{array}{cccc}
1 & \mathrm{r}_{12} & \cdots & \mathrm{r}_{1 \mathrm{~m}} \\
\mathrm{r}_{21} & 1 & \cdots & \mathrm{r}_{2 \mathrm{~m}} \\
\vdots & \vdots & & \vdots \\
\mathrm{r}_{\mathrm{n} 1} & \mathrm{r}_{\mathrm{n} 2} & \ddots & 1
\end{array}\right)
$$

(3) Calculate the eigenvalues and eigenvectors of the matrix

From the characteristic equation of $\mathrm{R}$

$$
|\mathrm{R}-\lambda \mathrm{I}|=0
$$

M non-negative eigenvalues are obtained, and they are arranged in order from the largest to the smallest

$$
\lambda_{1} \geqslant \lambda_{2} \geqslant \lambda_{3} \cdots \geqslant \lambda_{m} \geqslant 0
$$

According to

$$
\left\{\begin{array}{c}
(\mathrm{R}-\lambda \mathrm{I}) \text { a } i=0 \\
\text { a } \mathrm{i} \text { a } \mathrm{i}=1
\end{array} \quad \mathrm{i}=1,2,3, \cdots, \mathrm{m}\right.
$$

Each eigenvalue $\lambda_{i}$ corresponds to a unit eigenvector

$$
a_{i}=\left(a_{i 1}, a_{i 2}, \cdots, \quad a_{i m}\right)
$$

Thus the principal component can be obtained

$$
Z_{i}=a_{i} X=a_{i l} X_{1}+a_{12} X_{2}+\cdots+a_{i m} X_{m}
$$

The principal component of the calculated result can describe the percentage of information carried by the original variable. When the extraction cumulative 
variance contribution rate is more than $80 \%$, it is considered that the original information is basically retained, and it can be extracted as the main component [35-36].

The data operation of this method is realized by SPSS 20. 0 software and Excel software.

\subsubsection{Analysis methods for technical efficiency of EPHS}

Under the guidance of Data Envelopment Analysis (DEA) that is the best constructed non-parametric efficiency measurement method so far. The efficiency of EPHS is measured, that is, based on multiple input indicators and multiple output indicators of EPHS, linear programming was used to evaluate the implementation of essential public health service programs. Through DEA, the technical efficiency of EPHS in al1 137 counties and districts in Shandong Province from 2014 to 2019 can be obtained.

DEA requires that the total number of evaluation indexes should be less than half of the number of decision-making units [37]. In the production process of economic units, decision-making units usually have constant returns to scale and variable returns to scale. Therefore, these two situations should all be taken into consideration when studying the efficiency of decision-making units. The measurement models of efficiency of decision-making units are correspondently divided into two situations, namely CCR model and BBC model [38-39].

CCR model assumes Constant Returns to Scale (CRS), and the technical efficiency obtained by CCR model contains the components of scale efficiency, so it is often 
referred to as comprehensive technical efficiency. The nonlinear programming model of the CCR model is expressed as

$$
\begin{gathered}
\max \frac{\sum_{r=1}^{q} u_{r} y_{r k}}{\sum_{i=1}^{m} v_{i} x_{i k}} \\
\text { s. t. } \frac{\sum_{r=1}^{q} u_{r} y_{r j}}{\sum_{i=1}^{m} v_{i} x_{i j}} \leqslant 1 \\
\mathrm{v} \geqslant 0 ; \mathrm{u} \geqslant 0 \\
\mathrm{i}=1,2, \cdots, \mathrm{m} ; \mathrm{r}=1,2, \cdots, \mathrm{q} ; \mathrm{j}=1,2, \cdots, \mathrm{n}
\end{gathered}
$$

Then let $\mathrm{u}=\mathrm{tu}$ and $\mathrm{v}=\mathrm{tv}$, so the nonlinear model (1-9) is transformed into an equivalent linear programming model

$$
\begin{gathered}
\max \frac{\sum_{r=1}^{q} u_{r} y_{r k}}{\sum_{i=1}^{m} v_{i} x_{i k}} \\
\text { s. t. } \sum_{r=1}^{q} u_{r} y_{r j}-\sum_{i=1}^{m} v_{i} x_{i j} \leqslant 0 \\
\sum_{i=1}^{m} v_{i} x_{i k}=1 \\
\mathrm{i} \geqslant 1,2, \cdots, \mathrm{m} ; \mathrm{r}=1,2, \cdots, \mathrm{q} ; \mathrm{j}=1,2, \cdots, \mathrm{n}
\end{gathered}
$$


The dual model of model $(1-10)$ is

$$
\begin{gathered}
\min \theta \\
\text { s. t. } \sum_{j=1}^{n} \lambda_{j} x_{i j} \leqslant \theta x_{i k} \\
\sum_{j=1}^{n} \lambda_{j} y_{r j} \geqslant y_{r k} \\
\lambda \geqslant 0 \\
\mathrm{i}=1,2, \cdots, \mathrm{m} ; \mathrm{r}=1,2, \cdots, \quad \mathrm{q} ; \mathrm{j}=1,2,
\end{gathered}
$$

In the dual model (1-11), $\lambda$ represents the linear combination coefficient of DMU, and the optimal solution $\theta$ of the model represents the efficiency value. The range of $\theta$ is $(0,1]$.

The CCR dual model (1-11) measures the inefficiency to the extent that each input can be reduced in proportion to the given output, so it is called the input-oriented CCR mode1.

In actual production, many production units are not in the optimal scale production state, so the technical efficiency derived from the CCR model includes the scale efficiency component. In 1984, Banke, Charnes and Cooper proposed a DEA model for estimating scale efficiency, which was referred to as BCC model in subsequent literature [40]. The BCC model is based on Variable Returns to Scale (VRS), and the technical efficiency obtained excludes the influence of scale, so it is 
called "Pure Technical Efficiency" (PTE) [41-42].

The BCC model is based on the CCR dual model with additional constraints $\sum_{j=1}^{n} \lambda_{j}$ $=1(\lambda \geqslant 0)$, which can make the production scale of projection point in the same level as that of DMU evaluated [43].

$\min \theta$

s. t. $\sum_{j=1}^{n} \lambda_{j} x_{i j} \leqslant \theta x_{i k}$

$$
\sum_{j=1}^{n} \lambda_{j} y_{r j} \geqslant y_{r k}
$$

$$
\sum_{j=1}^{n} \lambda_{j}=1
$$

$$
\begin{gathered}
\lambda \geqslant 0 \\
i=1,2, \cdots, m ; r=1,2, \cdots, q ; j=1,2, \cdots, n
\end{gathered}
$$

The dual programming formula of BCC model (1-12) is as follows,

$$
\max \sum_{r=1}^{s} u_{r} y_{r k}-u_{0}
$$

s. t. $\quad \sum_{r=1}^{q} u_{r} y_{r j}-\sum_{i=1}^{m} v_{i} x_{i j}-u_{0} \leqslant 0$

$$
\sum_{i=1}^{m} v_{i} x_{i k}=1
$$




$$
\begin{gathered}
\mathrm{v} \geqslant 0 ; \quad \mathrm{u} \geqslant 0 ; \quad u_{0} \text { free } \\
i=1,2, \cdots, m ; r=1,2, \cdots, q ; j=1,2, \cdots, n
\end{gathered}
$$

This part of operation was realized by Max DEA 8 software and Excel software.

The DEA model requires that all data entering the model must be positive. This study adopted the method of power coefficient transformation analysis to transform the scores of each principal component of the output indicators to ensure that the values of subsequent DEA were positive.

If the principal component score was recorded as $Z$ and the principal component score transformed by the efficiency coefficient method was recorded as $X$, then the conversion formula of the efficiency coefficient method is

$$
X=0.1+0.9 \frac{(Z-\operatorname{minZ})}{\operatorname{maxZ}-\min Z}
$$

Min $Z$ represents the minimum value of the principal component score, Max $Z$ represents the maximum value of the principal component score, and $\mathrm{X}$ is within the interval of $[0.1,1][44-47]$.

The data operation of this method was realized by SPSS 20.0 software and Exce1 software.

\subsubsection{Analysis method for technical efficiency trend of EPHS}

After obtaining the efficiency (comprehensive technical efficiency, pure technical 
efficiency, and scale efficiency) of the EPHS in all 137 counties and districts in Shandong Province from 2014 to 2019, this study analyzed the efficiency trend over the six years. The analysis of the efficiency trend includes two parts, namely the trend analysis of the efficiency (comprehensive technical efficiency, pure technical efficiency, scale efficiency) and the trend analysis of the proportion of comprehensive technical efficiency effective counties.

The analysis method of the efficiency trend was to average the annual efficiency of 137 counties and districts to obtain the average annual efficiency of the province, and then analyze the trend of the efficiency of EPHS in Shandong Province from 2014 to 2019.

The analysis method for the trend of the proportion of counties with effective comprehensive technical efficiency was to calculate the proportion of counties with effective comprehensive technical efficiency in all 137 counties. After obtaining the annual proportion, the trend analysis of the proportion of counties and districts with effective technical efficiency of EPHS in Shandong Province from 2014 to 2019 was carried out.

\section{3 Data quality control}

Shandong Province summarized the statistical survey report of essential public health service programs with districts and counties as the main body, and the data reported by districts and counties were reviewed by users at provincial and municipal levels. City-level users review county-level users within their jurisdiction, and 
provincial-1evel users review city-level users within their jurisdiction. Provincial users would report to the National Health and Family Planning Commission after review.

A variety of assessment methods can ensure the quality of data submission, such as self-examination by grass-roots institutions, comprehensive assessment at the county level, random inspection and review at the city level and above, etc. Provincial and prefecture-1evel assessments are carried out at least once a year.

The annual assessment of provincial-level, prefecture-level, county-level and county-1evel grassroots medical and health institutions covered $100 \%$ of their jurisdictions. Reward and punishment mechanisms were implemented in the assessment of the quality of data filling.

\section{Empirical results}

\section{1 Results of output indicators classification}

Through the correlation matrix analysis of 24 output indicators of EPHS, we found that the correlation coefficients of most of the correlation matrices are greater than 0.3. All the KM0 values were greater than 0.80, indicating good applicability. The results of Bartlett' s sphericity test were all $\mathrm{P}<0.05$, and the original variables were not independent of each other. The results showed that the output indicators had a good correlation and are suitable for principal component analysis.

Based on the principal component extraction of 24 output indicators, the 
obtained principal component variance contribution rate showed that the characteristic roots of the first seven principal components of output indicators were all greater than 1 (Table 2).

Table 2 showed that the cumulative total variance contribution rate was $87.09 \%$, meaning that the seven principal components extracted could better summarize the main information of output index.

Table 2 The variance contribution rate of the principal component of the output index

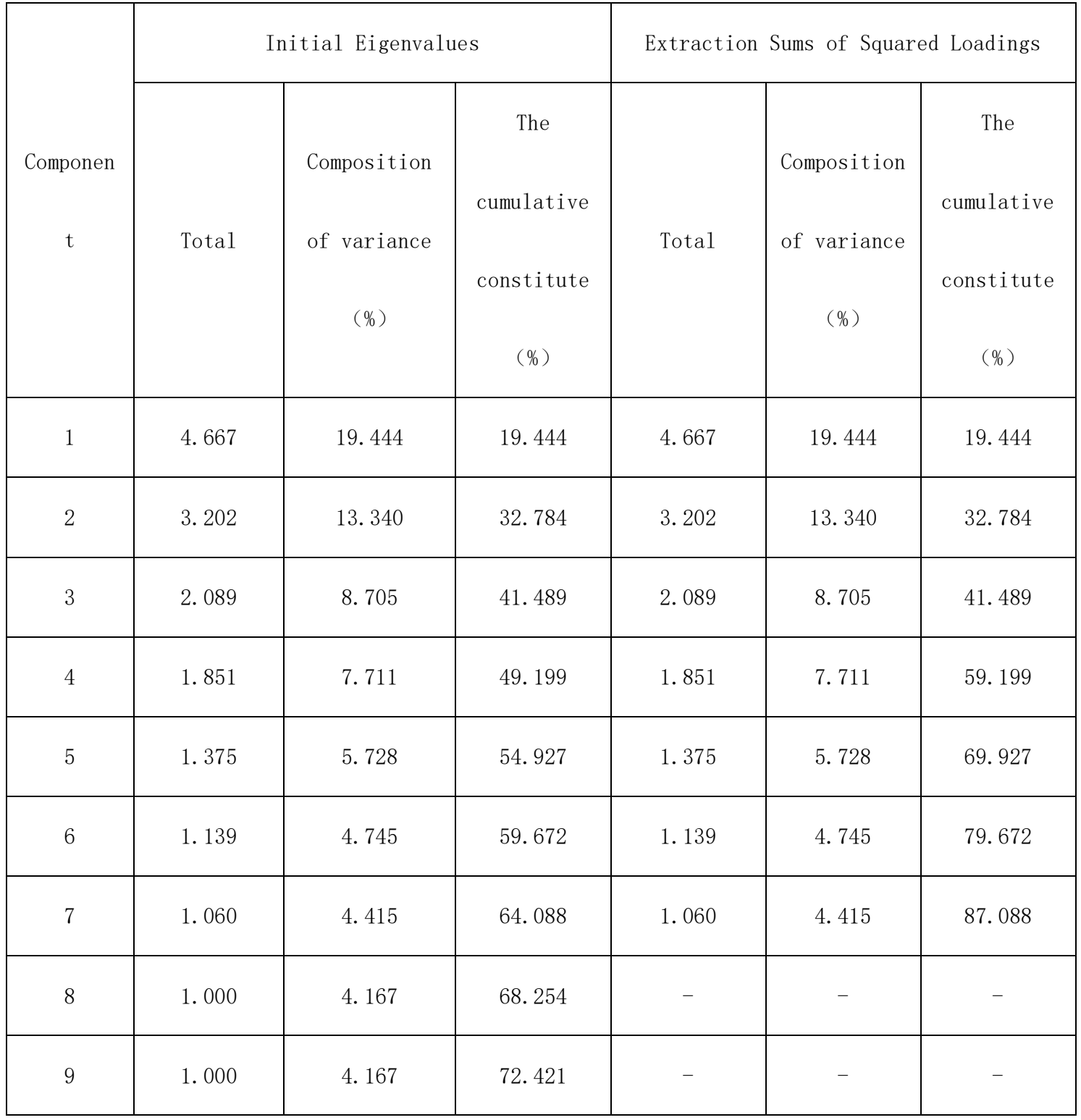




\begin{tabular}{|c|c|c|c|c|c|c|}
\hline 10 & 1. 000 & 4. 167 & 76.588 & - & - & - \\
\hline 11 & 1.000 & 4. 167 & 80.754 & - & - & - \\
\hline 12 & 1.000 & 4. 167 & 84.921 & - & - & - \\
\hline 13 & 0.961 & 4. 003 & 88.924 & - & - & - \\
\hline 14 & 0.633 & 2. 639 & 91.563 & - & - & - \\
\hline 15 & 0.464 & 1. 933 & 93.495 & - & - & - \\
\hline 16 & 0.452 & 1.885 & 95.380 & - & - & - \\
\hline 17 & 0.287 & 1. 196 & 96.577 & - & - & - \\
\hline 18 & 0.245 & 1. 019 & 97.596 & - & - & - \\
\hline 19 & 0.197 & 0.822 & 98.418 & - & - & - \\
\hline 20 & 0.163 & 0.677 & 99. 096 & - & - & - \\
\hline 21 & 0.127 & 0.527 & 99.623 & - & - & - \\
\hline 22 & 0.055 & 0.231 & 99.854 & - & - & - \\
\hline 23 & 0.029 & 0.119 & 99.973 & - & - & - \\
\hline 24 & 0.006 & 0.027 & 100.000 & - & - & - \\
\hline
\end{tabular}

1=Filing rate of health records, 2=Filing rate of electronic health records, $3=$ Utilization rate of health records, 4= Number of Health Education Talks, 5= Number of Health Lectures Attended, 6= Certificate issuance rate, $7=$ Neonatal visit rate, $8=$ Child health management rate, $9=$ Early pregnancy enrollment rate, 10= Postpartum visit rate, 11= Health management rate for the elderly, $12=$ Standard management rate of Hypertensive Patients, $13=$ Blood pressure control rate of management population, $14=$ Standard management rate of patients with type 2 diabetes, $15=$ Glucose control rate of management population, 16= Standard management rate of patients with severe semen 
concentration, $17=$ Tuberculosis patient management rate, 18= Regular drug taking rate in patients with tuberculosis, 19= Traditional Chinese Medicine health management rate for the elderly, $20=$ Traditional Chinese Medicine health management rate of children aged 0 to 36 months, 21= Reporting rate of infectious diseases, 22= Timely reporting rate of infectious diseases, 23= Public health emergency information reporting rate, 24= Health and Family Planning Supervision and Co-management Information Reporting Rate。

Orthogonal rotation of the extracted principal components was carried out to form the rotation component matrix of the output index after rotation. Finally, after dimensionality reduction and classification of 24 output indicators, 7 principal components were formed.

As shown in the Table 3, the seven newly extracted principal component output indicators were named as health management services for women, children and the elderly, health management services for traditional Chinese medicine, health management services for patients with chronic diseases, health education services, residents' health records management services, health management services for patients with severe mental disorders, and health management services for tuberculosis patients.

Table 3 Principal component naming of output index

\begin{tabular}{|c|c|c|}
\hline The principal & Indicators significantly related to principal components and & named \\
components & their loads & \\
\hline
\end{tabular}




\begin{tabular}{|c|c|c|}
\hline $\mathrm{F} 1$ & $\begin{array}{l}\text { Neonatal visit rate }(0.588) \text { 、Child health management rate } \\
(0.569) \text {, Early pregnancy enrollment rate }(0.283) \text {, Postpartum } \\
\text { visit rate }(0.642) \text {, Health management rate for the elderly } \\
(0.615)\end{array}$ & $\begin{array}{l}\text { health management services } \\
\text { for women, children and the } \\
\text { elderly }\end{array}$ \\
\hline $\mathrm{F} 2$ & $\begin{array}{l}\text { Traditional Chinese Medicine health management rate of } \\
\text { children aged } 0 \text { to } 36 \text { months (0.369)、Traditional Chinese } \\
\text { Medicine health management rate for the elderly (0.602) }\end{array}$ & $\begin{array}{l}\text { health management services } \\
\text { for traditional Chinese } \\
\text { medicine }\end{array}$ \\
\hline F3 & $\begin{array}{l}\text { Standard management rate of Hypertensive Patients ( } 0.761 \text { ), } \\
\text { Blood pressure control rate of management population }(0.581) \text {, } \\
\text { Standard management rate of patients with type } 2 \text { diabetes } \\
(0.748) 、 \text { Glucose control rate of management population } \\
(0.616)\end{array}$ & $\begin{array}{l}\text { health management services } \\
\text { for patients with chronic } \\
\text { diseases }\end{array}$ \\
\hline $\mathrm{F} 4$ & $\begin{array}{l}\text { Number of Health Education Talks (0.840)、Number of Health } \\
\text { Lectures Attended }(0.780)\end{array}$ & health education services \\
\hline F5 & $\begin{array}{l}\text { Filing rate of electronic health records }(0.646) 、 \text { Filing rate } \\
\text { of health records }(0.588) \text {, Utilization rate of health records } \\
(0.843)\end{array}$ & $\begin{array}{l}\text { residents' health records } \\
\text { management services }\end{array}$ \\
\hline F6 & $\begin{array}{l}\text { Standard management rate of patients with severe semen } \\
\text { concentration }(0.523)\end{array}$ & $\begin{array}{l}\text { health management services } \\
\text { for patients with severe } \\
\text { mental disorders }\end{array}$ \\
\hline F7 & $\begin{array}{l}\text { Tuberculosis patient management rate }(0.263) \text {, Regular drug } \\
\text { taking rate in patients with tuberculosis }(0.491)\end{array}$ & $\begin{array}{l}\text { health management services } \\
\text { for tuberculosis patients }\end{array}$ \\
\hline
\end{tabular}


Finally, the newly extracted 7 principal components that processed by the efficiency coefficient method represented 24 original output indicators, and entered the DEA for calculation, completing the process of simplifying the 24 redundant output indicators into 7 principal component indicators.

\section{2 DEA analysis result}

Based on the above-mentioned principal component analysis and efficiency coefficient analysis results, further EPHS efficiency analysis was carried out. We eliminated decision-making units with incomplete indicators in the database, and no longer analyzed their results. Thence 124 decision-making units were included in the analysis in 2014, 132 in 2015, 137 in 2016, 132 in 2017, 137 in 2018 and 137 in 2019 .

\subsubsection{Results of comprehensive technical efficiency score}

As shown in the Figure 1, the average comprehensive technical efficiency of EPHS in Shandong Province showed a slight downward trend from 2014 to 2019. Comprehensive technical efficiency decreased from 0.8896 in 2014 to 0.8753 in 2019.

From 2014 to 2019, the average pure technical efficiency of EPHS in Shandong Province was kept at 0.99 (Figure 2). 
The average scale efficiency of EPHS in Shandong Province showed a slight downward trend from 0.8871 in 2014 to 0.8744 in 2019 (Figure 3).

It can be explained by the above result that the main reason for the decline in the technical efficiency of EPHS in Shandong Province was the decline in scale efficiency.

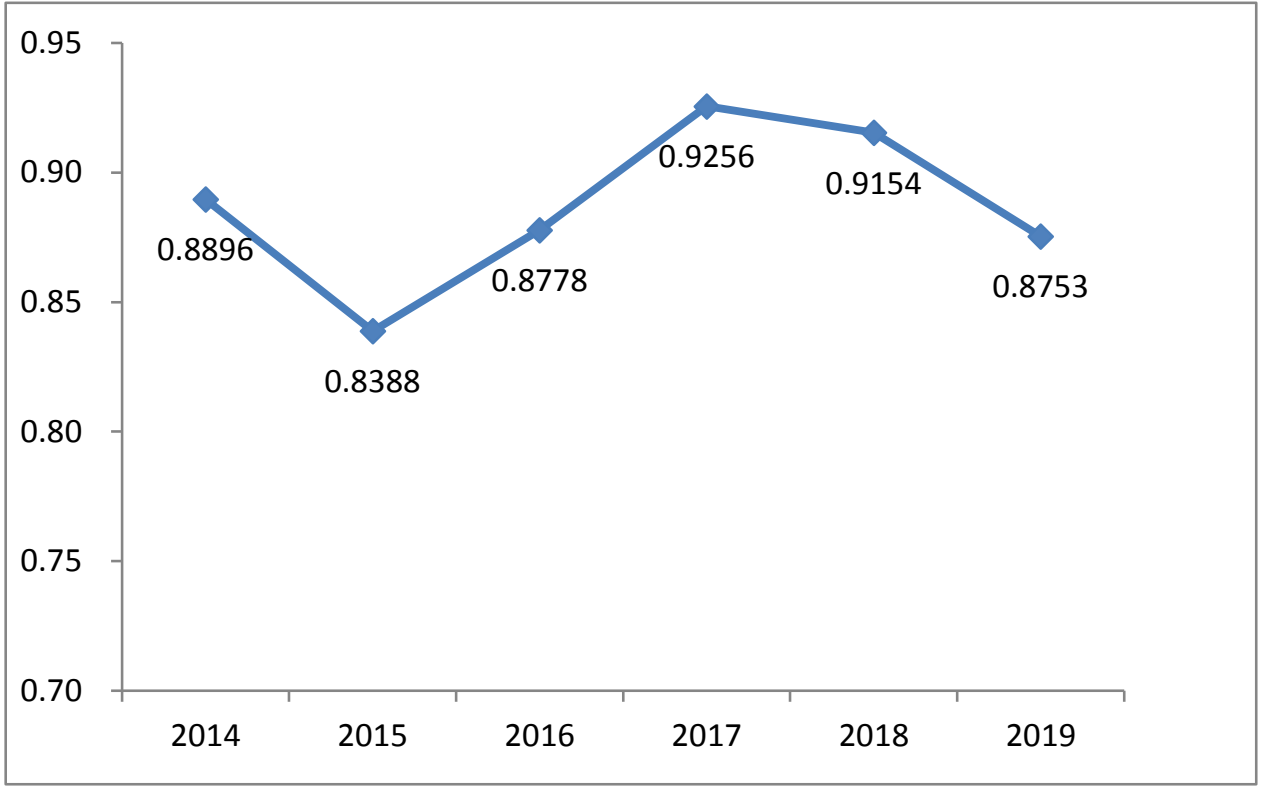

Figure 1 The average comprehensive technical efficiency of EPHS in Shandong Province from 2014 to 2019 


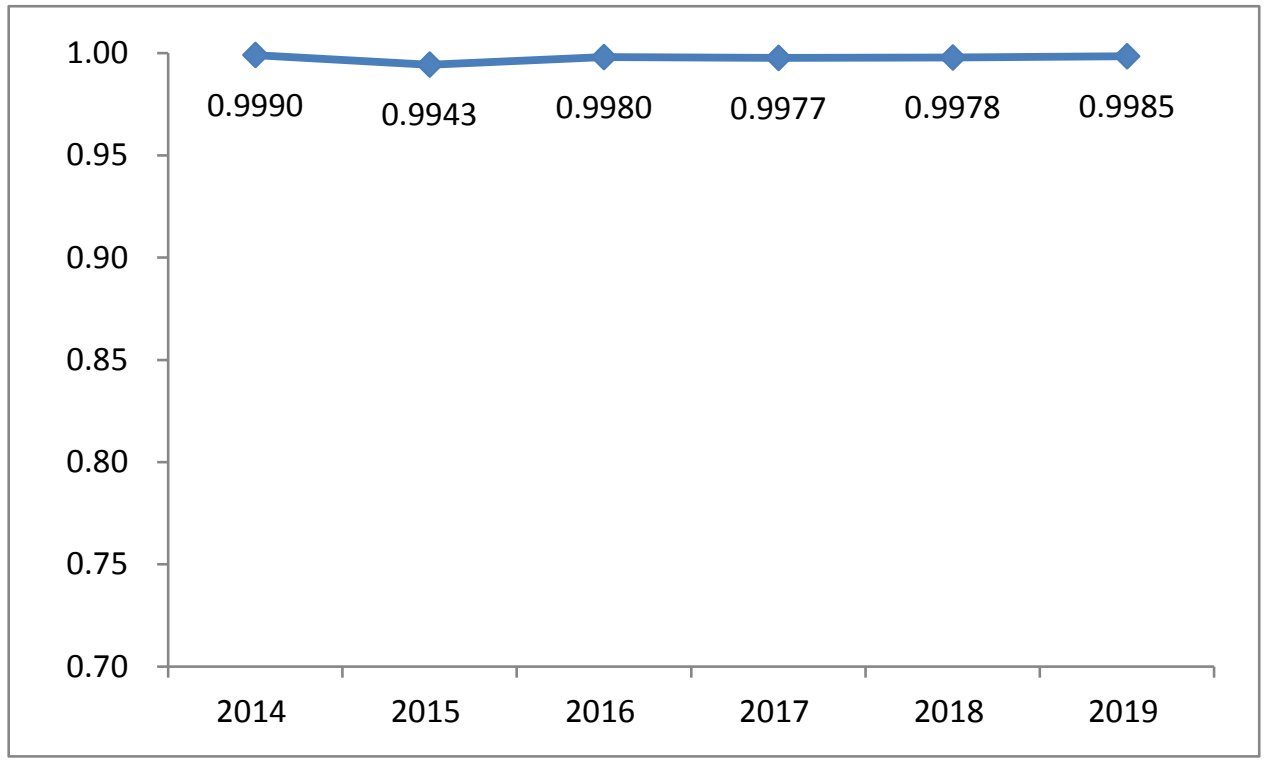

Figure 2 The average pure technical efficiency of EPHS in Shandong Province from 2014 to 2019

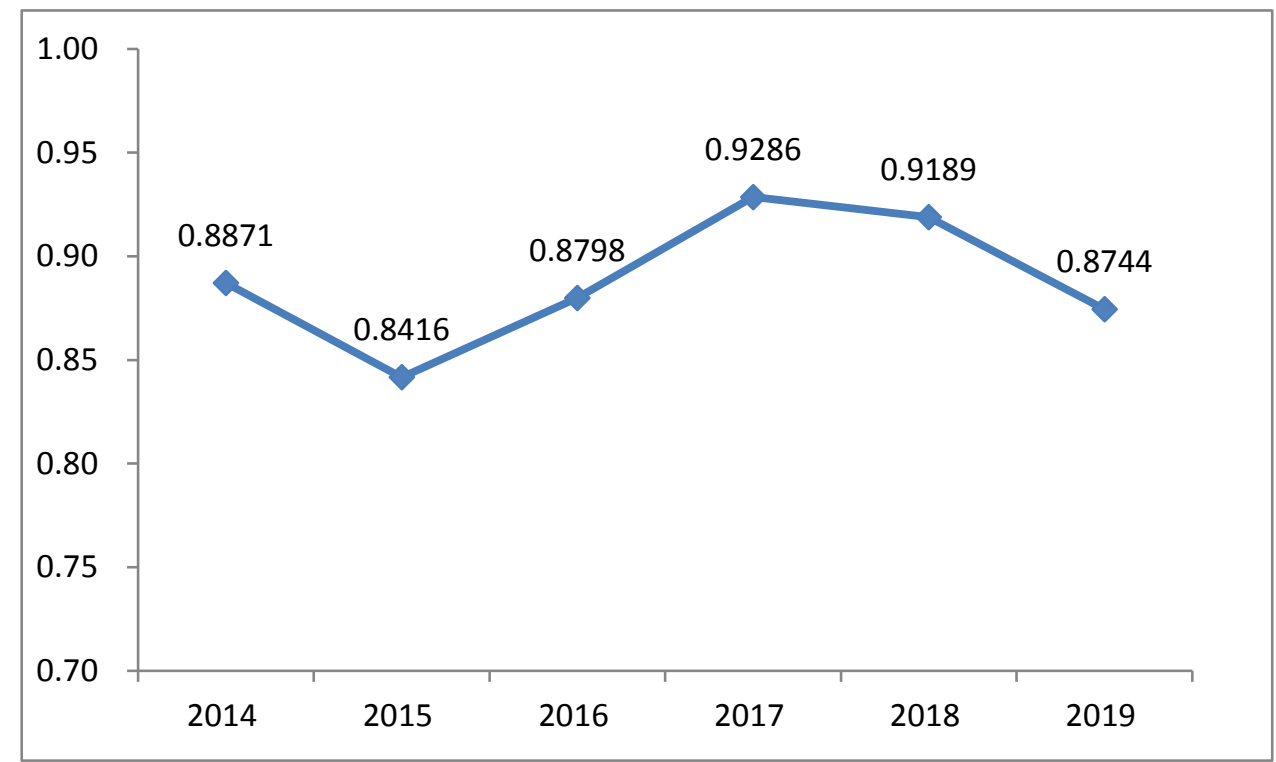

Figure 3 The average scale efficiency of EPHS in Shandong Province from 2014 to 2019

\subsubsection{Results of the proportion of counties with effective technical efficiency}

The proportion of counties and districts with the comprehensive technical efficiency of EPHS in Shandong Province was increased from 15. 3\% in 2014 to 21. 9\% in 2019 (Figure 4). 
But the proportion of counties with the pure technical efficiency decreased from 38. $0 \%$ in 2014 to $35.9 \%$ in 2019 (Figure 5).

Figure 6 showed the proportion of counties with scale efficiency of EPHS in Shandong Province from 2014 to 2019. The proportion of counties and districts showed an upward trend, rising from $14.8 \%$ in 2014 to $22.6 \%$ in 2019, increasing by $7.8 \%$.

The increasing proportion of effective counties and districts in the comprehensive technical efficiency of EPHS in Shandong Province was mainly due to the increasing proportion of effective counties and districts in the scale efficiency and the good performance of effective counties and districts in the pure technical efficiency.

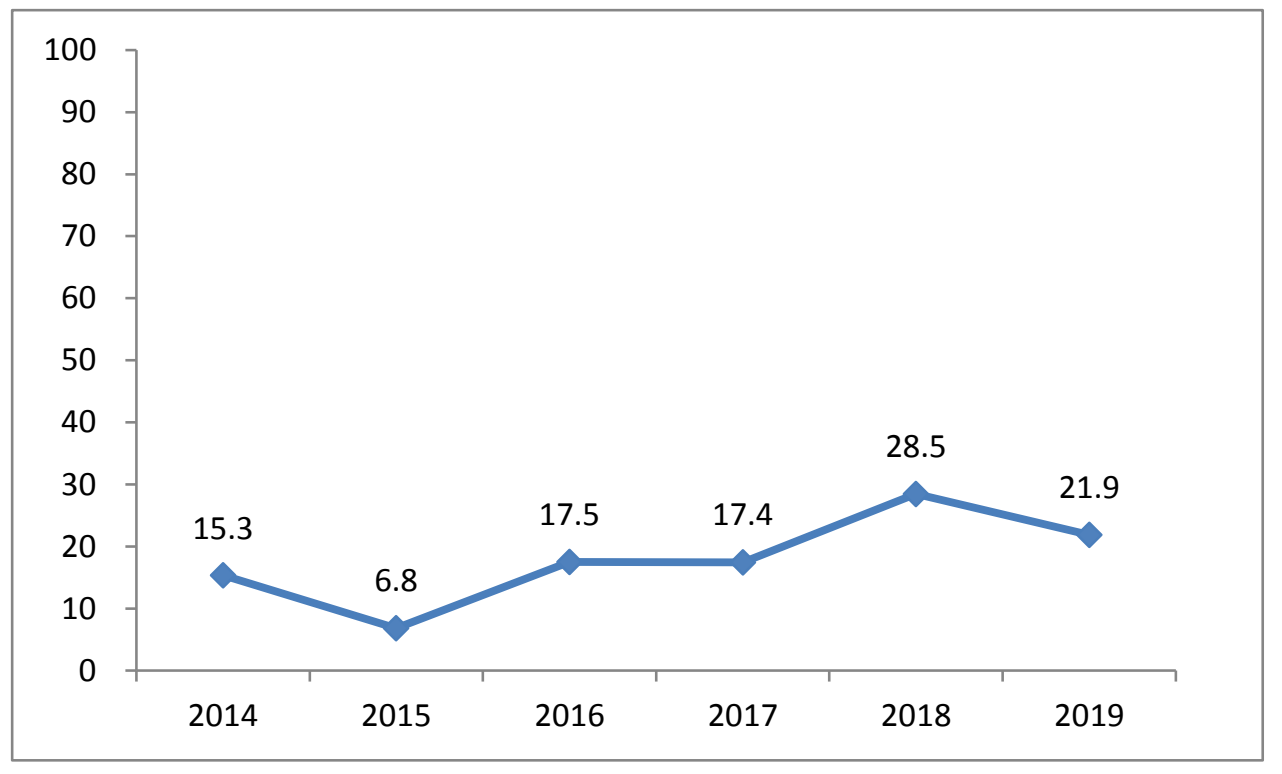

Figure 4 The proportion of counties and districts with effective comprehensive technical efficiency of EPHS in Shandong Province from 2014 to 2019 


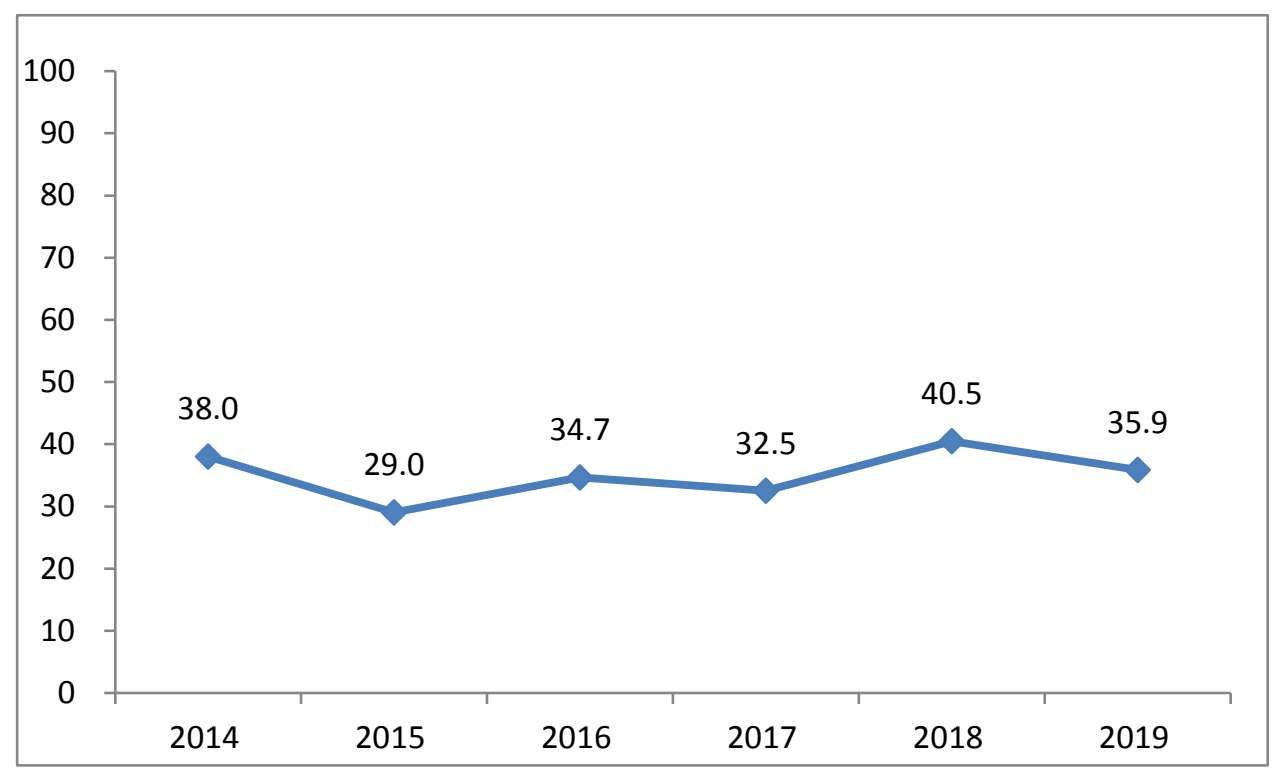

Figure 5 The proportion of counties and districts with effective pure technical efficiency of EPHS in Shandong Province from 2014 to 2019

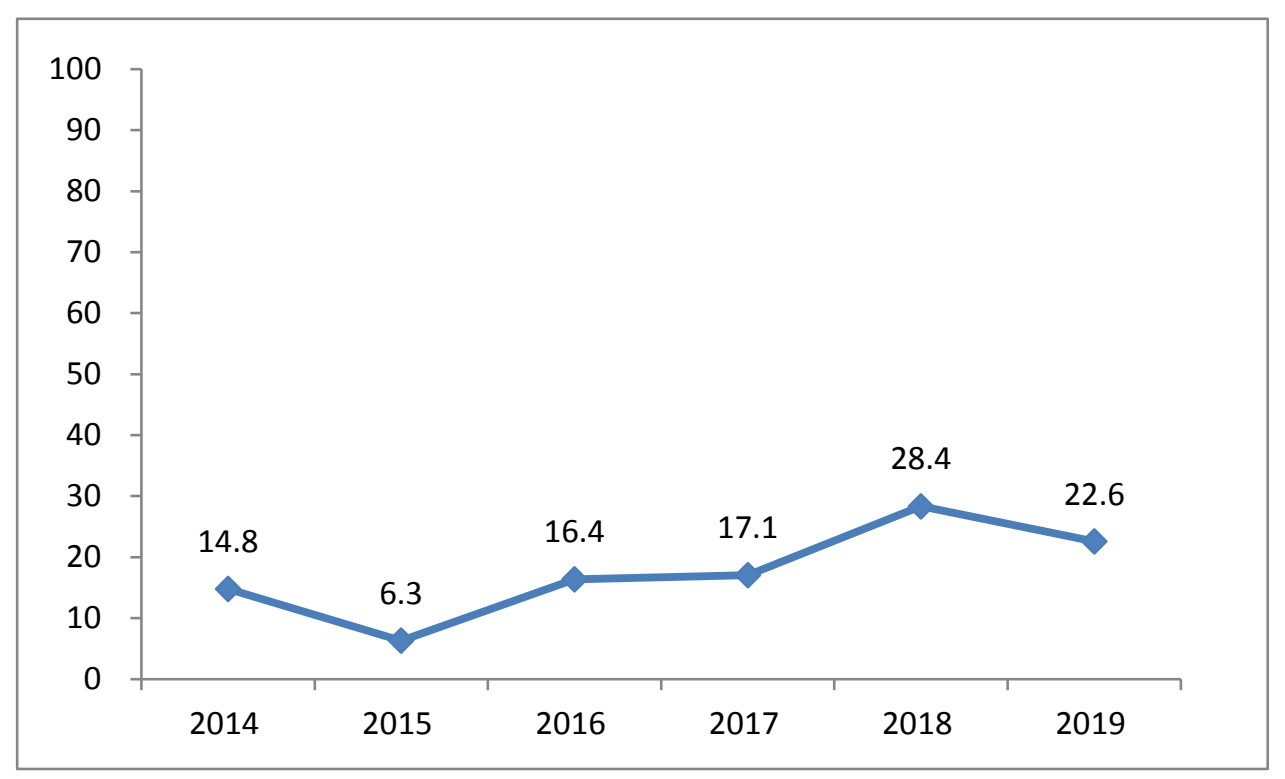

Figure 6 The proportion of counties and districts with effective scale efficiency of EPHS in Shandong Province from 2014 to 2019

\section{Discussion}

In the context of the new normal of economic development, subsidies for EPHS were 
still increasing year by year, and the investment was huge [48]. If this trend continued, the sustainability of EPHS would be challenged. Under the current level of investment and funding, full and effective use of resources was a powerful way to resolve this contradiction. Increasing the ratio of input to output was the essence of improving resource utilization efficiency. The prerequisite for studying the efficiency of EPHS was to understand the current efficiency status, and to analyze whether the technical efficiency was effective or ineffective through scientific measurement. Therefore, the purpose of this study was to fully understand the status quo of the technical efficiency of EPHS and provide a basis for the next step of analyzing efficiency influencing factors and efficiency improvement strategies.

There were a few studies on the technical efficiency of EPHS, and the existing research results shown that the technical efficiency of EPHS was not fully effective [49-50]. The reasons for the inefficiency of the technical efficiency of EPHS were concentrated in the efficiency of scale, which was mainly reflected in insufficient investment, which required further increase in capital and manpower investment [51]. At the same time, the input-output indicators of some studies only considered available data, rather than selecting indicators based on the relevance of service program activities [52]. This has led to the phenomenon of incomplete inclusion of input-output indicators. The scientific and accuracy of the research would be deeply affected [53].

Our research found that the average comprehensive technical efficiency of EPHS 
in Shandong Province from 2014 to 2019 showed a downward trend, but the decline was sma1l. Among them, the average value of pure technical efficiency hardly changed, while the average value of scale efficiency showed a downward trend. Therefore, the main reason for the decline in the technical efficiency of EPHS in Shandong Province was the decline in scale efficiency. The decline in scale efficiency indicated that the scale and total amount of resource inputs such as program funds and personnel in EPHS were insufficient in the actual reality [54].

From 2014 to 2019, the ratio of effective comprehensive technical efficiency of EPHS in Shandong Province to all counties and districts has shown a upward trend. Among them, the proportion of counties with effective pure technical efficiency was higher than the proportion of counties with efficient scale each year. At the same time, the increase in the proportion of counties with effective scale efficiency was higher than the increase in the proportion of counties with effective pure technical efficiency. Therefore, the increasing proportion of effective counties and districts in the comprehensive technical efficiency of EPHS in Shandong Province was mainly due to the increasing proportion of effective counties and districts in the scale efficiency and the good performance of effective counties and districts in the pure technical efficiency. In the implementation of EPHS, counties with effective pure technical efficiency could have standardized program management, perfect personnel training and good service quality [55-56]. And the counties with effective scale efficiency could guarantee sufficient investment scale in the implementation of EPHS, that was the investment of capital and personnel could fully 
meet the operation of EPHS [57].

At the same time, although the proportion of counties with effective scale efficiency was on the rise, the proportion of counties with effective scale efficiency was lower than the proportion of counties with effective pure technical efficiency each year. This showed that although the investment scale of Shandong Province in the counties was gradually sufficient, there was still a phenomenon of insufficient resource investment in most counties. Insufficient investment in basic public health service resources affected the proportion of counties with effective scale efficiency in EPHS in Shandong Province, which in turn lead to a lower proportion of counties with effective comprehensive technical efficiency.

The results showed that the low proportion of the county ratio of the effective comprehensive technical efficiency of EPHS in Shandong Province was due to the low proportion of the county ratio of the effective scale efficiency and the problem of insufficient resource input, which would ultimately affect the sustainability of the implementation of EPHS. Therefore, scale efficiency was the key to further improve the comprehensive technical efficiency of EPHS and ensure the sustainability of programs. Further increase in resource input would have important implications for the sustainable development of EPHS.

In summary, the technical efficiency of EPHS in Shandong Province showed an upward trend on the whole, but there was still room for improvement. Among them, scale efficiency was the key to further improve the comprehensive technical efficiency. The study found that scale efficiency is the reason for lowering the 
comprehensive technical efficiency of EPHS in Shandong Province. In other words, the scale efficiency in EPHS in Shandong Province needs to be increased. At the same time, it is also necessary to continue to maintain a good state of pure technical efficiency of EPHS.

Future research should focus on the influencing factors and improvement measures of the scale efficiency of EPHS. At present, there are many gaps in the study of technical efficiency of EPHS. This study explores the status quo and factors of technical efficiency of EPHS. The results showed that the scale efficiency of EPHS was an important factor affecting technical efficiency. Therefore, it is suggested that future research should focus on the influencing factors and improvement measures of the scale efficiency of EPHS.

\section{Conclusions}

This study provides an empirical picture of the technical efficiency of EPHS in Shandong Province from 2014 to 2019. The research has demonstrated that the technical efficiency of EPHS in Shandong Province has shown a slight downward trend, and the main reason for its downward trend was the decline in scale efficiency. The scale efficiency in EPHS affected the technical efficiency and would ultimately threaten the sustainable development of EPHS. It is recommended that future research directions focus on the influencing factors and improvement measures of the scale efficiency of EPHS. 


\section{References}

[1] Project Fund Supervision and Service Center of National Health and Family Planning Commission. 2010-2014 National Basic Public Health Service Project Performance Assessment Special Report Collection [R]. Beijing: Project Fund Supervision and Service Center of National Health and Family Planning Commission, 2016.

[2] Hongmei. Analysis of the problems existing in the fund management and use of basic public health service projects and their solutions[J]. China Health Industry, 2018, 15(6) : 102-103.

[3] Liu Haitao, Zhang Rui, Sun Cheng, et al. Problems and countermeasures in the fund management and use of basic public health service projects[J]. Bingtuan Medicine, $2017(3)$ : 73-75.

[4] National Health Development Research Center of the National Health and Family Planning Commission. Investigation report on residents' health inquiries at key contact points for comprehensive health reform at the grassroots level (2014 2016) [R]. Beijing: Health Development Research Center of National Health and Family Planning Commission, 2017.

[5] Qin Jiangmei. Progress of national basic public health service project. China Public Health, 2017, 033 (009): 1289-1297.

[6] Wang Qianyun, Yu Min. Research on primary health care system [J]. China Health Service Management, 2008, $25(7): 483-487$.

[7] Wang Yongzai. Analysis on the financial subsidy fund management of basic public health services [J]. China Agricultural Accounting, 2017 (12):36-38. 
[8] Hu Minghui. Analysis on fund performance audit of national basic public health service projects [J]. China Health Economy, 2017, 36(1):92-93.

[9] National Health and Family Planning Commission. Summary of China's Health and Family Planning Statistics in 2017 [M]. Beijing: Peking Union Medical College Press, 2017.

[10] Department of Basics, National Health and Family Planning Commission. Based on grassroots health for healthy China, promote the national basic public health service project in-depth development $[\mathrm{R}]$. Beijing: Department of Basics, National Health and Family Planning Commission, 2016.

[11] Mccarty A E, Armbruster S M , Moran J W. Performance Management in Public Health [M]. Collaborative Performance Management for Public Health. 2020.

[12] Bank W. World Development Report 1993[M]. Oxford University Press, 1993.

[13] John M. Hunter. World Development Report 1993: Investing in Health. [J]. communicable disease report cdr weekly, 1993, 3(30): 137 .

[14] Department of System Reform, National Health and Family Planning Commission. Monitoring Report on the Progress of Medical Reform in 2016 [R]. Beijing: Department of System Reform, National Health and Family Planning Commission, 2017.

[15] Bettcher D W, Sapirie S , Goon E H . Essential public health functions: results of the international Delphi study. [J]. 1998.

[16] World Health Organization. The World Health Report 2008: primary health care - now more than ever. [J]. World Health Report Primary Health Care Now More Than Ever, 2008, $25(7): 617$.

[17] National Health and Family Planning Commission Health Development Research Center. National Basic Public Health Service Fund Management and Operation Effect Investigation Research 
Report $[R]$. Beijing: Health Development Research Center of National Health and Family

Planning Commission, 2017.

[18] Jia Kang, Su Jingchun. On supply-side reform[J]. Management World, 2016, 000(003):1-24.

[19] Xu Kangning. Several theoretical issues and policy choices of supply-side reforms[J]. Modern Economic Research, 2016, (04): 7-11.

[20] Shao Yu. Supply-side reform: China's economic growth under the new normal [J]. New Finance, 2015, (12) : 17-21

[21] Xu Ziyi. On the supply-side reform under the new normal [J]. Business Manager, 2017(08):181.

[22] Zhou Wu, Xu Chunfeng. Analysis of the effect of basic public health service projects implemented by primary medical institutions[J]. Chinese Public Health Management, $2015(3): 339-340$

[23] Cheng Dier, Liu Guoen. Research on the Impact of Equalization of Public Health Services on People's Livelihood Achievement[J]. Statistics and Decision, 2019, 035(005):117-120.

[24] Qin Jiangmei, Zhang Yanchun, Zhang Lifang, et al. Fund management and operation effect analysis of national basic public health services[J]. Health Economics Research, 2018, No. $376(08): 58-61$

[25] Turner L. Bioethics and Religions: Religious Traditions and Understandings of Morality, Health, and Illness[J]. Health Care Analysis Hca Journal of Health Philosophy \& Policy, 2003, $11(3): 181$.

[26] The Reverend Alan Brown ObCR Senior Healthcare Studies Lecturer. Handbook of religion and health. Harold G. Koenig, Michael E. McCullough, David B. Larson 2001. Oxford: Oxford University Press. ISBN 019511866-9[J]. Spirituality \& Health International, 2010, 
$4(1): 55-55$.

[27] Walker B , Jr. The Future of Public Health: The Institute of Medicine' s 1988 Report [J]. Journal of Public Health Policy, 1989, 10(1):19-31.

[28] Novick L F . Public Health: Our Time of Challenge[J]. Journal of Public Health Management and Practice, 2020, 26.

[29] Lin Haiming, Du Zifang. Issues that should be paid attention to in the comprehensive evaluation of principal component analysis[J]. Statistical Research, 2013, 30(08): 25-31.

[30] Xie Suwen. Research on the application of mathematical models based on principal component analysis and factor analysis [D].

[31] Zhang Peng. Research on comprehensive evaluation based on principal component analysis [D]. Nanjing University of Science and Technology.

[32] Li Jinghua, Guo Yaohuang. Principal component analysis for multi-index evaluation method research-principal component evaluation[J]. Chinese Journal of Management Engineering, 2002, $16(1): 39-43$.

[33] Lin Haiming, Zhang Wenlin. The similarities and differences between principal component analysis and factor analysis and SPSS software-and discuss with Liu Yumei and Lu Wendai[J]. Statistical Research, $2005(03):$ 65-69.

[34] Dcz A, Guo Z A, Lyj A, et al. Comprehensive evaluation on anti-inflammatory and anti-angiogenic activities in vitro of fourteen flavonoids from Daphne Genkwa based on the combination of efficacy coefficient method and principal component analysis[J]. Journal of Ethnopharmacology, 2020, 268.

[35] Ma S , Dai Y . Principal component analysis based methods in bioinformatics studies[J]. 
Briefings in Bioinformatics, 2011(6):714-722.

[36] Wang Jinxiang, Wu Yuhua. The emergence and development of production frontier theory[J]. Journal of Harbin University of Commerce: Natural Science Edition, 2005(03):382-386.

[37] Mao Qing. Theoretical Research on Data Envelopment Analysis [J]. Science and Technology Communication, 2011, $000(001):$ 15-15.

[38] Sun Wei. Production resource allocation efficiency: production frontier theory and its application. Social Sciences Literature Press, 2000.

[39] Banker R D , Charnes A , Cooper W W. Some Models for Estimating Technical and Scale Inefficiencies in Data Envelopment Analysis[J]. Management Science, 1984, 30 (9) :1078-1092.

[40] Daniel 0sei, Selassi d’Almeida, Melvill 0 George, et al. Technical efficiency of public district hospitals and health centres in Ghana: a pilot study[J]. Cost Effectiveness \& Resource Allocation C/e, 2005, 3(1):9-9.

[41] Mohammed Bader, Mohamad Shamsher, Mohamed Ariff, et al. Cost, revenue, and profit efficiency of Islamic versus conventional banks: International evidence using data envelopment analysis[M]// Islamic Economic Studies. 2008.

[42] Coelli T . A multi-stage methodology for the solution of orientated DEA models [J]. Operations Research Letters, 1998, $23(3-5): 143-149$.

[43] Liu Baohua, Wu Xiaofan. Application of efficacy coefficient method in comprehensive evaluation of medical quality[J]. Chinese Medical Record, 2008(04):23-24.

[44] Li Xia, Gan Shengdao. Financial risk evaluation of non-profit organizations based on the efficiency coefficient method[J]. Research on Financial Issues, 2016, $000(004)$ : 88-94.

[45] Sun Zhenqiu. Comprehensive medical evaluation method and its application [M]. Chemical 
Industry Press, 2006.

[46] Qiu Dong. Systematic analysis of multi-index comprehensive evaluation methods [M]. China Statistics Press, 1991.

[47] Xu Juan. Research in Health Economics, 2014(2) :53-55.

[48] Wang Wei. Evaluation of the efficiency of basic public health services in Shandong Province based on DEA mode1[J]. Chinese Administration, 2014, $000(012)$ : 86-89.

[49] Wang Peng, Yang Xianxian, Zhou Xipeng, et al. Analysis on the efficiency of basic public health service projects in Chongqing in 2014[J]. Journal of Shanghai Jiaotong University (Medical Edition), 2016(7): 1054-1058.

[50] Zhang Guilin, Pan Xilong. Evaluation of Beijing Rural Basic Public Health Service Project Efficiency Based on Data Envelopment Analysis Method[J]. Journal of Peking University (Health Sciences), $2013(02): 264-268$.

[51] Ke Sisi, Cao Yi, Jiang Ming, et al. Analysis of the efficiency of basic public health services in primary medical and health institutions in Wuhan $[\mathrm{J}]$. Chinese Journal of Health Information Management, 2017, 14(004):589-593.

[52] Liang Huijie, Zhang Ye, Chao Zhengrong. Comparison of the efficiency difference of the multiple supply of basic public health services-Dased on the survey of four types of subjects in Urumqi [J]. Chinese Health Service Management, 2018, 035(003):231-235.

[53] Yang Chun, Wang Junshuang. Evaluation of Fund Utilization Efficiency of Community Basic Public Health Services in Tianjin Binhai New Area Based on Data Envelopment Analysis[J]. Chinese General Practice, 2015(13): 1510-1513.

[54] Lin Denan, Liang Liang, Liang Shi, et al. Evaluation of the efficiency of Shenzhen's 
community basic public health services based on data envelopment analysis $[J]$. Chinese Health Statistics, $2017(2): 284-287$.

[55] Liang Liang. Evaluation of the efficiency of Shenzhen's community basic public health services based on data envelopment analysis[D]. Guangzhou Medical University, 2015.

[56] Zhu Kejing, Liang Weiwen, Li Deyun. Evaluation of the efficiency of basic public health service items of community health service institutions in Zhuhai City based on data envelopment analysis[J]. Modern Medicine and Health 2020,36(12): 1781-1784.

[57] Yuan Xue. Comprehensive evaluation and efficiency analysis of national basic public health service projects in Zhengzhou City[D]. Zhengzhou University, 2018. 